NBER WORKING PAPER SERIES

\title{
THE ECONOMICS OF CRISIS INNOVATION POLICY: A HISTORICAL PERSPECTIVE
}

\author{
Daniel P. Gross \\ Bhaven N. Sampat \\ Working Paper 28335 \\ http://www.nber.org/papers/w28335
NATIONAL BUREAU OF ECONOMIC RESEARCH
1050 Massachusetts Avenue
Cambridge, MA 02138
January 2021

We thank Harvard Business School and the NBER Innovation Policy grant for financial support. This material is based upon work supported by the National Science Foundation under Grant No. 1951470. All errors are our own. The views expressed herein are those of the authors and do not necessarily reflect the views of the National Bureau of Economic Research.

NBER working papers are circulated for discussion and comment purposes. They have not been peer-reviewed or been subject to the review by the NBER Board of Directors that accompanies official NBER publications.

(C) 2021 by Daniel P. Gross and Bhaven N. Sampat. All rights reserved. Short sections of text, not to exceed two paragraphs, may be quoted without explicit permission provided that full credit, including $(\odot)$ notice, is given to the source. 
The Economics of Crisis Innovation Policy: A Historical Perspective

Daniel P. Gross and Bhaven N. Sampat

NBER Working Paper No. 28335

January 2021

JEL No. H12,H56,N42,N72,O31,O32,O38

\begin{abstract}
$\underline{\text { ABSTRACT }}$
Since the beginning of the COVID-19 pandemic, policymakers, researchers, and journalists have made comparisons to World War II. In 1940, a group of top U.S. science administrators organized a major coordinated research effort to support the Allied war effort, including significant investments in medical research which yielded innovations like mass-produced penicillin, antimalarials, and a flu vaccine. We draw on this episode to discuss the economics of crisis innovation. Since the objectives of crisis $R \& D$ are different than ordinary $R \& D$ (prioritizing speed, coordination, redundancy, and more), we argue that appropriate R\&D policy in a crisis requires going beyond the standard Nelson-Arrow framework for research policy.
\end{abstract}

\author{
Daniel P. Gross \\ Fuqua School of Business \\ Duke University \\ 100 Fuqua Drive \\ Durham, NC 27708 \\ and NBER \\ daniel.gross@duke.edu \\ Bhaven N. Sampat \\ Department of Health Policy and Management \\ Columbia University \\ 722 W 168th Street, Room 486 \\ New York, NY 10032 \\ and NBER \\ bns3@columbia.edu
}


The COVID-19 pandemic has highlighted the value of innovation in a crisis. Economics has a rich tradition of research on innovation policy, with intellectual roots in Nelson (1959) and Arrow (1962), who identified three features of innovation - indivisibility, inappropriability, and uncertainty - as reasons why $R \& D$ is likely underprovided in open markets relative to the socially optimal level. In articulating the intrinsic difficulties of achieving a first-best allocation of resources to $R \& D$ without government intervention, Nelson and Arrow provided the foundation for sixty years of scholarship on the economics of innovation and innovation policy.

The decades of research that followed would seem to make economics as a field well-positioned to advise crisis innovation policy. Yet with its focus on market failures in the supply of (generic) private R\&D in normal times, the canonical Nelson-Arrow paradigm that has guided economic thinking on innovation policy may not be the right framework for crisis innovation policy. Are crisis innovation problems different? What can we learn from past crises about optimal crisis policy? And does the economics of innovation policy need to expand its conceptual toolkit to confront the (potentially) distinctive features of crisis innovation?

While there is a subjective element to what counts as a crisis, in this paper we use recent and historical experience with crisis innovation to argue that crises put unique demands on the innovation system, some of which are beyond the scope of the Nelson-Arrow paradigm. As a result, optimal crisis innovation policy is likely different from optimal innovation policy in normal times. Few examples illustrate this more than the World War II crisis research effort, which was led by the U.S. Office of Scientific Research and Development (OSRD). We begin by describing how the OSRD approached crisis innovation. We then use the OSRD example to orient a discussion of the specific features of crisis innovation problems. We conclude by discussing the implications of crises for $\mathrm{R} \& \mathrm{D}$ in regular times and identify questions for future research.

\section{OSRD's Approach to Crisis R\&D}

The World War II effort was organized by the OSRD, which was created in June 1940 by order of President Roosevelt (originally as the National Defense Research Committee (NDRC)) to apply scientific research to military problems. Led by Vannevar Bush (then President of the Carnegie Institution of Washington, formerly Vice President at MIT), OSRD was explicitly a crisis research 
policy agency, comprised of two branches (NDRC and the Committee on Medical Research (CMR)) whose mission was to support R\&D in technologies and medical treatments to further national defense, as well as to lead the mobilization of U.S. science, coordinate the research efforts of other agencies, and advise the President. In describing its work, OSRD's executive secretary Irvin Stewart later wrote that "the need for speed hung like a sword over the head" of the organization (Stewart 1948). The urgency of its work shaped all of its policies, from research funding choices to indirect cost recovery, patents, coordination of research efforts, and decisions to invest not just in research but also production and diffusion. We describe five main features of the organization that may be useful to consider in contemplating a theory of crisis innovation. ${ }^{1}$

\section{Emphasis on applied research}

The OSRD funded applied research, with priorities set in collaboration with end users. The applied focus was a result of not only the nature of military R\&D problems, but also necessity: its leaders recognized that the time for basic research is before a crisis, and urgency meant that "the basic knowledge at hand had to be turned to good account" (Conant 1947). This stands in contrast to the emphasis of Bush (1945) and Nelson-Arrow on funding basic research.

\section{Prioritizing results}

In choosing what to fund, whom to fund, and how to incentivize their work, OSRD was primarily focused on getting results. It favored R\&D contractors "with the facilities and the manpower which promised the best results in the shortest possible time" (Stewart 1948) over cost or distributional concerns. Its indirect cost policy, novel at the time, provided generous reimbursement for overhead (50 percent for universities, 100 percent for firms) to make it worthwhile for these organizations to loan out their top talent. This priority was also seen in its patent policy, which specified whether the government or the contractor received title to inventions. Bush determined it was important to secure firms' cooperation and often awarded them patent rights on OSRD-funded invention, reserving only a royalty-free license for military use.

\section{Coordination}

The need for speed also led OSRD to take a heavy hard in coordinating research efforts, beyond

${ }^{1}$ For a more complete view of the OSRD and its administration of the World War II research effort, and the resulting lessons for crisis R\&D management, see Gross and Sampat (2020b). 
simple funding. In the penicillin effort, this involved facilitating information flow among researchers without compromising potentially proprietary data. In the malaria program, where thousands of compounds were studied, coordination entailed surveying the portfolio of candidates and distributing them to make sure all bases were covered and to avoid unnecessary duplication. Still other forms of coordination were prominent in OSRD's effort to develop radar technology: throughout the war, radar development was centered at the MIT Radiation Lab, where OSRD co-located scientists and engineers working on interrelated problems. In several of these efforts (e.g., radar and penicillin) coordination also took place with researchers in Allied countries.

\section{Redundancy}

In contexts where there was solution uncertainty, OSRD often funded multiple rivalrous efforts. In medicine, the CMR supported not only a large effort to make synthetic penicillin, but also, in collaboration with other government agencies, a distinct effort to scale-up the production of natural penicillin. In atomic energy, unclear which method of separating uranium isotopes would be viable for large-scale production, and with urgency due to concurrent German pursuit of the bomb, the OSRD invested in multiple methods until one proved successful.

\section{Diffusion}

The OSRD's work did not end with R\&D. Conant (1947) emphasized OSRD's role in "connect[ing] effectively the laboratory, the pilot plant, and the factory with each other and with the battlefront." It had specific offices to aid in getting new technology into the hands of soldiers, supporting smallbatch initial production runs, field tests, and even battlefield deployment. Tight links between the OSRD and the military enabled rapid feedback and continual tweaking to ensure the technology met the needs in the field. CMR was also active in testing and promoting utilization of therapies and procedures developed by researchers it funded. Much of its funding was devoted to clinical trials. In the case of penicillin, the CMR helped support manufacturing as well, though it had less of a role than other agencies such as the War Production Board.

Each of these features - the focus on applied research, prioritizing results, supporting coordination, investing in parallel efforts, and funding diffusion - reflected the focus on crisis resolution. Whether by default or design, the fact the OSRD was a new organization and preceded the postwar research bureaucracy might also have allowed it to be agile and adaptive. 
Over the course of the war, the OSRD developed numerous technologies key to the Allied victory, including radar, mass produced penicillin, malaria treatments and a range of other drugs, and the atomic bomb. Reflecting widespread belief that science and technology helped win the war, before the war was over Roosevelt asked Bush to draw lessons from the experience for how innovation "should be used in the days of peace ahead for the improvement of the national health, the creation of new enterprises bringing new jobs, and the betterment of the national standard of living." Bush's response, Science, The Endless Frontier, famously makes the case for government funding of basic science in peacetime. It does not explicitly draw lessons for crisis innovation, beyond emphasizing how important prewar basic science was for the OSRD effort and the need to redress disruptions to science caused by the war. Bush instead anticipated the market failure theory of innovation policy that would later become the bedrock of the economics of science. ${ }^{2}$

\section{Crisis Innovation and the Nelson-Arrow Paradigm}

For our purposes in this section, we define a crisis as an immediate, extreme threat to human life, prosperity, or freedom. Not all crises can be tackled with innovation, but in some-including disease, environmental catastrophe, and even war-science and technology can be powerful tools in the arsenal. Two basic features of crisis innovation problems are the large social returns to $\mathrm{R} \& \mathrm{D}$ and a need to act quickly, before losses mount or the threat grows more difficult to contain. Crises often present an asymmetric loss function, where overinvesting in R\&D is less costly than undershooting. ${ }^{3}$ Equally notably, crisis innovation problems are not resolved by invention alone: production and diffusion, including human factors, can be just as important as the innovation itself and may need to be accounted for from the earliest stages of R\&D.

We can begin by connecting crisis innovation to the Nelson-Arrow paradigm and its descendants, drawing both parallels and distinctions. Though it shares an interest in welfare, to a first order, the goal of crisis innovation is crisis resolution, rather than generic technological progress. This

\footnotetext{
${ }^{2}$ Bush (1945) writes, "We cannot expect industry adequately to fill the gap ... basic research is essentially noncommercial in nature. It will not receive the attention it requires if left to industry."

${ }^{3}$ In principle, there are multiple ways to model an asymmetric loss function. It can be written into a welfare criterion directly. It can also be a result of social returns to $R \& D$ being more concave than the costs are convex. The challenge in practice is that the shape of the costs and benefits are unknown. However, an awareness of this asymmetry (and its magnitude) should encourage policies that err on the side of overinvestment. A similar argument has been made by Kremer et al. (2020) in the context of advanced market commitments for vaccines.
} 
will usually require attacking specific innovation problems with applied (versus basic) R\&D and prioritizing speed over other considerations. Urgency is not necessarily outside of the scope of the Nelson-Arrow framework: time value is a standard concept in economic models. Likewise, exceptionally large social benefits of innovation are not beyond the scope of traditional models per se. Crises may even magnify traditional Nelson-Arrow causes of market failure like uncertainty or appropriability, especially when $R \& D$ investments are made early on in a crisis, before the scale of the problem or technical feasibility are fully understood and before it is known whether or how much private R\&D efforts will be rewarded. Through the lens of Nelson-Arrow, a crisis merely underscores the importance for a generous government funder.

Even so, sharp changes in the basic parameters of traditional economic models of innovation can have material effects on optimal innovation policies. For example, the need for speed and very large returns may justify funding (overlapping) parallel research efforts and collaboration amongst R\&D performers to increase the rate of arrival - activities which could be considered inefficient in regular times. The urgency of a crisis may even necessitate trading off long-run efficiency for short-term impact. In the most extreme crises, the intertemporal elasticity of substitution is infinite: without short-run impact there may not be a long run, a tension not contemplated by Nelson and Arrow but which was arguably the case in World War II, a major armed conflict against a global hegemon. At a minimum, ambiguity over what an efficient policy is - due to the uncertain and fast-moving nature of crises, and intertemporal tradeoffs - may require accepting the risk of allocative inefficiency, and a recognition that ex-ante efficient policy may not be ex-post efficient.

As OSRD discovered, appropriability is an especially complicated subject in a crisis. On the one hand, private participants in crisis innovation efforts bring advanced R\&D capabilities to bear on innovation problems, including physical and human capital; must be assured return on investment to incentivize their participation; and often expect to retain patents. On the other hand, public funders of crisis innovation efforts may want to guard against profiteering, and many observers argue that patents produced with public funding should be public property or freely licensed - especially in a crisis (Kilgore 1943, Sampat 2020). Even worse, patents can slow down technological progress. Yet there is also a possibility that the appropriability problem is softened rather than amplified in a crisis, when private actors may be motivated by a spirit of generosity, a sense of social responsibility, 
or reputational benefits. This is surely the case for some crises: in World War II, for example, many individuals and organizations - though not all, to be sure - were actively seeking to contribute to the war effort on the home front out of a sense of patriotism.

To summarize, the principal questions asked by Nelson-Arrow are (i) what is the first-best level of $R \& D$ investment, and (ii) whether this optimum will be realized by competitive markets. For the reasons we discussed, R\&D market failures may be amplified in a crisis, and the Nelson-Arrow arguments for public R\&D funding are even more pointed in crises as in ordinary times. Moreover, a crisis may justify a flood of public funding, even on efficiency grounds: theory tells us that R\&D investments should increase with social returns. ${ }^{4}$ Given that it is difficult to precisely specify optimal funding, it may be better to err towards being overly generous, as the cost of overshooting the target is likely to be far lower than the cost of undershooting.

Yet as we see with the OSRD, crisis innovation might require activities which often do not feature in economic models of innovation, like coordination, redundancy, and investments in downstream production and diffusion-including in production capacity at risk, before a candidate technology has been fully developed or proven to work. From a systems engineering perspective, redundancy is valuable as insurance against $R \& D$ failure and has been a standard feature of crisis innovation from penicillin or atomic fission to a COVID-19 vaccine.

Crisis innovation efforts also tend to feature extensive coordination. End users such as the military (in World War II) or hospitals (in the COVID-19 pandemic) can often give valuable guidance to crisis R\&D efforts, with an intimate knowledge of the technological challenge and field conditions to which a solution must be adapted - whether it is a radar system that must function in freezing conditions or a vaccine that can be preserved without deep-freeze storage. As the OSRD illustrates, coordination across research efforts can likewise be useful, such as in ensuring that the full range of research strategies are pursued, or in the sharing of information (e.g., technical details or interim successes and failures) that can benefit many R\&D projects.

Though in normal circumstances considered distinct from innovation, production and distribution are part and parcel of crisis innovation policy: when speed is of the essence, organizers of crisis R\&D

\footnotetext{
${ }^{4}$ In Dasgupta and Stiglitz (1980), for example, when the benefits of an innovation or the time value (discount rate) grows large, so should the number of (concurrent) attempts at a solution.
} 
may wish to ensure that finished technology can be produced at scale and deployed as soon as the $\mathrm{R} \& \mathrm{D}$ is complete. Economic models of innovation often focus on $\mathrm{R} \& \mathrm{D}$ and take diffusion as given, which in normal times is usually an equilibrium outcome of product markets. In a crisis, however, getting technology deployed is as consequential a problem as the R\&D itself, and in practice, crisis innovation policy typically considers what investments to make in these downstream activities and may include a government buyer. The conditions under which to build production capacity at risk, how much, and for how many developing technologies is not one that is addressed by prevailing models of innovation, but like many of the other distinctive features of crisis innovation problems, we believe it is ripe for attention. Until then - and perhaps even then-historical experience offers insights to support both research and future crisis response.

\section{Implications for R\&D in Regular Times}

What are the implications of crises for $\mathrm{R} \& \mathrm{D}$ in regular times? One lesson is the strategic value of basic research and public investments in additional techno-scientific capabilities, including growing the stock of scientific human, physical, and institutional capital across a range of fields. These are the resources that crisis innovation will draw from - such as COVID-19 vaccines, which are rooted in basic understanding of mRNA. The recognition that the existing stock of basic research was instrumental to the World War II research effort was among Bush's reasons for arguing in Science, The Endless Frontier that basic science should be funded in peacetime.

Another lesson is the importance of designing R\&D-funding and R\&D-performing institutions that can pivot quickly in a crisis. As a de novo agency, OSRD was advantaged in this regard, with little precedent or constraint — not to mention significant funding and access to much of the country's best scientific talent, who made themselves available to the war effort. But other features - like trusted leadership, close relations with other agencies and end users, and a catalog of domestic scientists and facilities for different R\&D problems - likely helped and could be emphasized more by science policy institutions today. Perhaps most importantly, there was effectively one agency overseeing government R\&D. OSRD was both a central authority and a clearinghouse of information, with a direct line to the President. Rather than competing or colliding, other agencies were synchronized under OSRD guidance. To our knowledge, there is no standby agency today which is explicitly 
charged with coordinating research along the lines of OSRD's role in World War II, though history suggests such an agency can be invaluable when crises arise.

Crises can also have effects on innovation that outlive the crisis itself. Though OSRD was decommissioned in 1947, it laid the foundation for postwar R\&D funding, and its work was continued by a constellation of federal agencies. Many research subjects were positively shocked by the war effort, while research in other areas was interrupted; Stewart (1948) writes that some subjects were even "born of war." In recent work (Gross and Sampat 2020a), we have shown that the OSRD had a lasting effect on the direction and domestic geography of U.S. technological innovation, catalyzing long-run growth in fields and locations which were mobilized by the wartime research effort, with downstream effects on entrepreneurship and employment. Anecdotally, the wartime research effort endowed many of the participating firms with IP, absorptive capacity, and other advantages that persisted in the postwar era. It seems possible that the COVID-19 research effort could have similar impacts on biomedical innovation, potentially unleashing a new era of vaccine innovation much as the World War II penicillin program did for antibiotics, among others.

Though economists' understanding of crisis innovation is growing, many questions remain. What is the optimal level of appropriability in a crisis, and how can crisis innovation be supported without bestowing post-crisis market power? How elastic are different organizations, researchers, and fields in their ability to pivot to crisis innovation problems on short notice? How detrimental are crises to fields that are not the focus of crisis R\&D? Are there examples of failed crisis innovation programs, and if so, what can be learned from them? In our view, however, the most important question is whether there is a reliable way to determine which fields should be research funding targets during regular times in preparation for (unpredictable) emergencies. 


\section{References}

Arrow, Kenneth. 1962. "Economic Welfare and the Allocation of Resources for Invention," in The Rate and Direction of Inventive Activity: Economic and Social Factors, Princeton: Princeton University Press, pp. 609-626.

Bush, Vannevar. 1945. Science, the Endless Frontier: A Report to the President. Washington: Government Printing Office.

Conant, James B. 1947. "The Mobilization of Science for the War Effort," American Scientist, Vol. 35, No. 2, pp. 195-210.

Dasgupta, Partha and Joseph Stiglitz. 1980. "Industrial Structure and the Nature of Innovative Activity," The Economic Journal, Vol. 90, No. 358, pp. 266-293.

Gross, Daniel P. and Bhaven N. Sampat. 2020a. Inventing the Endless Frontier: The Effects of the World War II Research Effort on Post-war Innovation. NBER Working Paper No. 27375.

— 2020b. Organizing Crisis Innovation: Lessons from World War II. NBER Working Paper No. 27909.

Kilgore, Harley M. 1943. "The Science Mobilization Bill," Science, Vol. 98, No. 2537, pp. 151-152.

Kremer, Michael, Jonathan Levin, and Christopher M. Snyder. 2020. "Advance Market Commitments: Insights from Theory and Experience," in AEA Papers 85 Proceedings, Vol. 110, pp. 269-73.

Nelson, Richard R. 1959. "The Simple Economics of Basic Scientific Research," Journal of Political Economy, Vol. 67, No. 3, pp. 297-306.

Sampat, Bhaven N. 2020. "Whose Drugs are These?" Issues in Science and Technology, Vol. 36, No. 4, pp. 42-48.

Stewart, Irvin. 1948. Organizing Scientific Research for War. Boston: Little, Brown and Company. 